\title{
Near and Closer Relations in Bitopology
}

\author{
R. Chitralekha ${ }^{1}$, M. Anitha ${ }^{2}$ and N. Meena ${ }^{3}$ \\ ${ }^{I}$ Department of Mathematics, Rani Anna Govt. College, Tirunelveli-8, Tamilnadu, India. \\ Email: chitralekha2761981@gmail.com \\ ${ }^{2}$ Department of Mathematics, Rani Anna Govt. College, Tirunelveli-8, Tamilnadu, India. \\ ${ }^{3}$ Department of Mathematics, M.D.T.Hindu College, Tirunelveli, Tamilnadu, India. \\ Affiliated to Manonmaniam Sundaranar University, Tirunelveli-12, India
}

\begin{abstract}
Dvalishvili studied the concepts of near relations and closer relations in topology in 2005. In 2009, these relations were further investigated by Thamizharasi and Thangavelu. Recently the authors introduced the weak forms of near and closer relations in topology. In this paper, the weak forms of near and closer relations in bitopology have been discussed .
\end{abstract}

Keywords: Near relations, closer relations, topology, bitopology, b-open sets, semi-open sets. 2010 AMS Subject Classification: 54A05, 54A10, 54E55.

\section{INTRODUCTION AND PRELIMINARIES}

Topologists extended the notions of semi-open, $\alpha-$ open, pre-open, $\beta$-open ,b-open and $\mathrm{b}^{\#}$-open sets in topology to bitopological spaces. The concepts of near relations and closer relations in topology that were discussed in [5, 12]. These notions are further investigated in [10]. Recently the authors introduced the weak forms of near and closer relations in topology. The purpose of this paper is to investigate these relations in bitopological settings. Throughout this paper $(X, \tau)$ is a topological space and $\left(X, \tau_{1}, \tau_{2}\right)$ is a bitopological space, $i, j=1,2$ and $i \neq j$. Also $A$ and $B$ are the subsets of $\mathrm{X} . \quad C l_{\mathrm{i}} \mathrm{A}=$ the closure of $\mathrm{A}$ and $I n t_{\mathrm{i}} \mathrm{A}=$ the interior of A with respect to $\tau_{i .}$.

Definition 2.1: A is called

(i).regular open [9] if $\mathrm{A}=\operatorname{Int} \mathrm{Cl} \mathrm{A}$

(ii).semiopen[6] if there exists an open set $\mathrm{U}$ with $\mathrm{U} \subseteq$ $\mathrm{A} \subseteq C l \mathrm{U}$

(iii). preopen [7] if there exists an open set $U$ with $\mathrm{A} \subseteq \mathrm{U} \subseteq C l \mathrm{~A}$

(iv).b -open [2] if $\mathrm{A} \subseteq C l$ Int $\mathrm{A} \cup \operatorname{Int} C l \mathrm{~A}$

(vi). $\mathrm{b}^{\#}$-open [11] if $\mathrm{A} \subseteq C l$ Int $\mathrm{A} \cup \operatorname{Int} C l \mathrm{~A}$

(vii). $\alpha$-open [7] if $\mathrm{A} \subseteq \operatorname{Int} \mathrm{Cl}$ Int $\mathrm{A}$.

(viii). $\beta$-open [1] if $\mathrm{A} \subseteq C l$ Int $C l \mathrm{~A}$.
The Complements of sets in Definition 2.1 are called the corresponding closed sets. The corresponding interior and closure operators can be defined in the usual manner. The following lemma will be useful in sequel.

\section{Lemma 2.2:}

(i). $\operatorname{sInt} \mathrm{A}=\mathrm{A} \cap C l \operatorname{Int} \mathrm{A}$ and $\mathrm{sClA}=\mathrm{A} \cup \operatorname{Int} C l \mathrm{~A}$.

(ii).pInt $\mathrm{A}=\mathrm{A} \cap I n t C l \mathrm{~A}$ and $\mathrm{pClA}=\mathrm{A} \cup C l$ Int $\mathrm{A}$.

(iii). $\alpha$ Int $\mathrm{A}=\mathrm{A} \cap C l$ Int $C l \mathrm{~A}$ and $\alpha \mathrm{ClA}=\mathrm{A} \cup C l$ Int $C l \mathrm{~A}$

(iv). $\beta \operatorname{Int} \mathrm{A}=\mathrm{A} \cap C l$ Int $C l \mathrm{~A}$ and $\beta C l \mathrm{~A}=\mathrm{A} \cup \operatorname{Int} C l$ Int $\mathrm{A}$

Definition 2.3: A is called

(i).ij-regular open [10] if $\mathrm{A}=\operatorname{Int} \mathrm{i}_{\mathrm{i}} C \mathrm{l}_{\mathrm{j}} \mathrm{A}$

(ii).ij-semiopen[10] if there exists an i-open set $\mathrm{U}$ with $\mathrm{U} \subseteq \mathrm{A} \subseteq C l_{\mathrm{j}} \mathrm{U}$

(iii).ij-preopen [10] if there exists an i-open set $\mathrm{U}$ with $\mathrm{A} \subseteq \mathrm{U} \subseteq C l_{\mathrm{j}} \mathrm{A}$

(iv).ij-b -open [10] if $\mathrm{A} \subseteq C l_{\mathrm{j}} I n t_{\mathrm{i}} \mathrm{A} \cup I n t_{\mathrm{i}} C l_{\mathrm{j}} \mathrm{A}$

(v). $. \mathrm{j}-\mathrm{b}^{\#}$-open [3] if $\mathrm{A}=C l_{\mathrm{j}} I n t_{\mathrm{i}} \mathrm{A} \cup I n t_{\mathrm{i}} C l_{\mathrm{j}} \mathrm{A}$

(vi).ij- $\alpha$-open [10] if $\mathrm{A} \subseteq I n t_{\mathrm{i}} C l_{\mathrm{j}} I n t_{\mathrm{i}} \mathrm{A}$.

(vii).ij- $\beta$-open [10] if $\mathrm{A} \subseteq C l_{\mathrm{i}} I n t_{\mathrm{j}} C l_{\mathrm{i}} \mathrm{A}$. 


\section{Available online at www.ijrat.org}

The Complements of sets in Definition 2.3 are called the corresponding closed sets. Further $\mathrm{A}$ is ij-regular closed if and only if $\mathrm{A}=C l_{\mathrm{j}} I n t_{\mathrm{i}} \mathrm{A}$. The following lemmas have been established in [10].

Lemma 2.5: $\mathrm{A}$ is

(i).ij-semiopen $\Leftrightarrow \mathrm{A} \subseteq C l_{\mathrm{j}} I n t_{\mathrm{i}} \mathrm{A}$.

(ii).ij-preopen $\Leftrightarrow \mathrm{A} \subseteq I n t_{\mathrm{i}} C l_{\mathrm{j}} \mathrm{A}$.

(iii).ij-b-closed $\Leftrightarrow I n t_{\mathrm{j}} C l_{\mathrm{i}} \mathrm{A} \cap C l_{\mathrm{i}} I n t_{\mathrm{j}} \mathrm{A} \subseteq \mathrm{A}$,

The concepts of $s \sin t_{\mathrm{ij}} \mathrm{A}$, and $\mathrm{s} C l_{\mathrm{ij}} \mathrm{A}$ can be defined in a usual way.

\section{Lemma 2.6:}

(ii)

$$
\begin{aligned}
& \mathrm{s} I n t_{\mathrm{ij}} \mathrm{A}=\mathrm{A} \cap C l_{\mathrm{j}} I n t_{\mathrm{i}} \mathrm{A} \\
& \mathrm{s} C l_{\mathrm{ij}} \mathrm{A}=\mathrm{A} \cup I n t_{\mathrm{j}} C l_{\mathrm{i}} \mathrm{A}
\end{aligned}
$$

\section{NEAR RELATIONS IN BITOPOLOGY}

The next proposition shows that Lemma 2.2 can be established in bitological settings.

\section{Proposition 3.1:}

(i). $\mathrm{A}$ is $\mathrm{ij}-\alpha$-open iff $\mathrm{A}=\mathrm{A} \cap I n t_{\mathrm{i}} C l_{\mathrm{j}} I n t_{\mathrm{i}} \mathrm{A}$ and $\mathrm{A}$ is $\mathrm{ij}-\alpha-$ closed iff $\mathrm{A}=\mathrm{A} \cup C l_{\mathrm{i}} I n t_{\mathrm{j}} C l_{\mathrm{i}} \mathrm{A}$.

(ii). $\mathrm{A}$ is ij-preopen iff $\mathrm{A}=\mathrm{A} \cap \operatorname{Int} t_{\mathrm{i}} C l_{\mathrm{j}} \mathrm{A}$ and $\mathrm{A}$ is $\mathrm{ij}$ preclosed iff $\mathrm{A}=\mathrm{A} \cup C l_{\mathrm{i}} I n t_{\mathrm{j}} \mathrm{A}$.

(iii). $\mathrm{A}$ is $\mathrm{ij}-\beta$-open iff $\mathrm{A}=\mathrm{A} \cap C l_{\mathrm{i}} I n t_{\mathrm{j}} C l_{\mathrm{i}} \mathrm{A}$ and $\mathrm{A}$ is $\mathrm{ij}-\beta$ closed iff $\mathrm{A}=\mathrm{A} \cup I n t_{\mathrm{i}} C l_{\mathrm{j}} I n t_{\mathrm{i}} \mathrm{A}$.

Proof:Suppose $\mathrm{A}$ is $\mathrm{ij}-\alpha$-open. Then $\mathrm{A} \subseteq I n t_{\mathrm{i}} C l_{\mathrm{j}} I n t_{\mathrm{i}} \mathrm{A}$ that implies $\mathrm{A}=\mathrm{A} \cap I n t_{\mathrm{i}} C l_{\mathrm{j}} I n t_{\mathrm{i}} \mathrm{A}$. Conversely let $\mathrm{A}=\mathrm{A} \cap I n t_{\mathrm{i}} C l_{\mathrm{j}} I n t_{\mathrm{i}} \mathrm{A}$. Then $\mathrm{A} \subseteq I n t_{\mathrm{i}} C l_{\mathrm{j}} I n t_{\mathrm{i}} \mathrm{A}$ that implies that $\mathrm{A}$ is $\mathrm{ij}$ - $\alpha$-open. This proves the first part of (i). Now suppose $\mathrm{A}$ is $\mathrm{ij}-\alpha$-closed. Then $\mathrm{A} \supseteq C l_{\mathrm{i}} I n t_{\mathrm{j}} C l_{\mathrm{i}} \mathrm{A}$ that implies $\mathrm{A}=\mathrm{A} \cup C l_{\mathrm{i}} I n t_{\mathrm{j}} C l_{\mathrm{i}} \mathrm{A}$. Conversely let $\mathrm{A}=\mathrm{A} \cup C l_{\mathrm{i}} I n t_{\mathrm{j}} C l_{\mathrm{i}} \mathrm{A}$. Then $\mathrm{A} \supseteq C l_{\mathrm{i}} I n t_{\mathrm{j}} C l_{\mathrm{i}} \mathrm{A}$ that implies $\mathrm{A}$ is ij- $\alpha$-closed. This proves (i). Other results in the proposition can be analogously established.

Remark 3.2: The above proposition motivates to define the closure and interior operators of a bitoplogical space in the following manner.

\section{Definition 3.3:}

(i). $\mathrm{p} I n t_{\mathrm{ij}} \mathrm{A}=\mathrm{A} \cap I n t_{\mathrm{i}} C l_{\mathrm{j}} \mathrm{A}$ and $\mathrm{p} C l_{\mathrm{ij}} \mathrm{A}=\mathrm{A} \cup C l_{\mathrm{i}} I n t_{\mathrm{j}} \mathrm{A}$. (ii). $\alpha I n t_{\mathrm{ij}} \quad \mathrm{A} \quad=\mathrm{A} \cap I n t_{\mathrm{i}} C l_{\mathrm{j}} I n t_{\mathrm{i}} \mathrm{A} \quad$ and $\quad \alpha C l_{\mathrm{ij}} \mathrm{A}=$ $\mathrm{A} \cup C l_{\mathrm{i}} I n t_{\mathrm{j}} C l_{\mathrm{i}} \mathrm{A}$.

(iii). $\beta I n t_{\mathrm{ij}} \quad \mathrm{A} \quad=\mathrm{A} \cap C l_{\mathrm{i}} I n t_{\mathrm{j}} C l_{\mathrm{i}} \mathrm{A}$ and $\beta C l_{\mathrm{ij}} \mathrm{A}=$ $\mathrm{A} \cup I n t_{\mathrm{i}} C l_{\mathrm{j}} I n t_{\mathrm{i}} \mathrm{A}$.

Definition 3.4: We say that

(i). $\mathrm{A}$ is ij-near to $\mathrm{B}$ if $\operatorname{In} t_{\mathrm{i}} \mathrm{A}=\operatorname{Int} t_{\mathrm{j}} \mathrm{B}$

(ii). $\mathrm{A}$ is ij-seminear to $\mathrm{B}$ if $\sin t_{\mathrm{i}} \mathrm{A}=\sin t_{\mathrm{j}} \mathrm{B}$

(iii). $\mathrm{A}$ is ij- $\alpha$-near to $\mathrm{B}$ if $\alpha \operatorname{Int} t_{\mathrm{i}} \mathrm{A}=\alpha \operatorname{Int} t_{\mathrm{j}} \mathrm{B}$

(iv). $\mathrm{A}$ is ij-prenear to $\mathrm{B}$ if $\mathrm{p} \operatorname{Int} t_{\mathrm{i}} \mathrm{A}=\mathrm{p} \operatorname{Int} \mathrm{B}$

(v). $\mathrm{A}$ is $\mathrm{ij}-\beta$-near to $\mathrm{B}$ if $\beta \operatorname{Int} t_{\mathrm{i}} \mathrm{A}=\beta \operatorname{Int} t_{\mathrm{j}} \mathrm{B}$

\section{Proposition 3.5:}

(i). A is ij-near to B if and only if B is ji-near to A.

(ii). $A$ is ij-seminear to $B$ if and only if $B$ is ji-seminear to $\mathrm{A}$.

(iii).A is ij- $\alpha$-near to B if and only if $B$ is $j i-\alpha$-near to A.

(iv).A ij- is prenear to B if and only if B is ji-prenear to A.

(v).A is ij- $\beta$-near to $B$ if and only if $B$ is $j i-\beta$-near to $A$.

Proof: Straight forward.

Proposition 3.6: Let $A$ and $B$ be any two subsets of $X$ such that $I n t_{\mathrm{i}} \mathrm{A} \in \tau_{\mathrm{j}}$ and $I n t_{\mathrm{j}} \mathrm{B} \in \tau_{\mathrm{i}}$. If $\mathrm{A}$ is $\mathrm{ij}$-seminear or $\mathrm{ij}-\alpha$-near or ij-pre-near or $\mathrm{ij}-\beta$-near to $B$ then $A$ is $i j-$ near to $\mathrm{B}$.

Proof: Suppose A is ij-seminear to $\mathrm{B}$. Then $\sin t_{\mathrm{i}} \mathrm{A}=$ $\operatorname{sInt} \mathrm{B}$ that implies

$\mathrm{A} \cap C l_{\mathrm{i}} \operatorname{Int}_{\mathrm{i}} \mathrm{A}=\sin t_{\mathrm{i}} \mathrm{A}=\sin t_{\mathrm{j}} \mathrm{B}=\mathrm{B} \cap C l_{\mathrm{j}} \operatorname{Int}_{\mathrm{j}} \mathrm{B} . \quad$ Now $I n t_{\mathrm{i}} \mathrm{A} \subseteq \operatorname{s} I n t_{\mathrm{i}} \mathrm{A}=\operatorname{s} I n t_{\mathrm{j}} \mathrm{B}=\mathrm{B} \cap C l_{\mathrm{j}} I n t_{\mathrm{j}} \mathrm{B} \subseteq \mathrm{B}$

that implies $I n t_{\mathrm{i}} \mathrm{A} \subseteq \mathrm{B}$. Since $\operatorname{Int} t_{\mathrm{i}} \mathrm{A} \in \tau_{\mathrm{j}}$ it follows that $I n t_{\mathrm{i}} \mathrm{A} \subseteq I n t_{\mathrm{j}} \mathrm{B}$. Similarly we can prove that $I n t_{\mathrm{j}} \mathrm{B} \subseteq I n t_{\mathrm{i}} \mathrm{A}$. This proves that $I n t_{\mathrm{i}} \mathrm{A}=I n t_{\mathrm{j}} \mathrm{B}$ that implies $\mathrm{A}$ is ij-near to $\mathrm{B}$. The other cases can be analogously proved.

\section{Proposition 3.7:}

(i).If $\mathrm{A}$ is $\mathrm{ij}$-regular open then $\mathrm{A}$ is $\mathrm{i}$-near to $C l_{\mathrm{j}} \mathrm{A}$.

(ii).If $A$ is $i j$-semiclosed or $\mathrm{ij}$ - $\alpha$-closed then $A$ is $\mathrm{j}$-near to $C l_{\mathrm{i}} \mathrm{A}$.

(iii).If $\mathrm{A}$ is ij-preclosed then $\mathrm{A}$ is $\mathrm{j}$-near to $C l_{\mathrm{i}} I n t_{\mathrm{j}} \mathrm{A}$.

(iv).If $\mathrm{A}$ is $\beta$-closed or $\mathrm{ij}$-b-closed or $\mathrm{ij}-\mathrm{b}^{\#}$-closed then $\mathrm{A}$ is i-near to $C l_{\mathrm{j}} I n t_{\mathrm{i}} \mathrm{A}$. 


\section{International Journal of Research in Advent Technology, Vol.7, No.1, January 2019 E-ISSN: 2321-9637 \\ Available online at www.ijrat.org}

Proof: Suppose A is ij-regular open. Then $\mathrm{A}=\operatorname{Int} t_{\mathrm{i}} C l_{\mathrm{j}} \mathrm{A}$ that implies $I n t_{\mathrm{i}} \mathrm{A}=\operatorname{In} t_{\mathrm{i}} C l_{\mathrm{j}} \mathrm{A}$. This proves that $\mathrm{A}$ is near to $C l_{\mathrm{j}} \mathrm{A}$ in $\left(\mathrm{X}, \tau_{\mathrm{i}}\right)$. This proves (i). If $\mathrm{A}$ is $\mathrm{ij}$-semiclosed then $I n t_{\mathrm{j}} \mathrm{A}=I n t_{\mathrm{j}} C l_{\mathrm{i}} \mathrm{A}$ that implies $\mathrm{A}$ is $\mathrm{j}$-near to $C l_{\mathrm{i}} \mathrm{A}$. If $\mathrm{A}$ is $\mathrm{ij}-\alpha$-closed then $C l_{\mathrm{i}} I n t_{\mathrm{j}} C l_{\mathrm{i}} \mathrm{A} \subseteq \mathrm{A}$ that implies $I n t_{\mathrm{j}} \mathrm{A}=I n t_{\mathrm{j}} C l_{\mathrm{i}} I n t_{\mathrm{j}} C l_{\mathrm{i}} \mathrm{A}=I n t_{\mathrm{j}} C l_{\mathrm{i}} \mathrm{A}$ that proves that $\mathrm{A}$ is $\mathrm{j}$ near to $C l_{\mathrm{i}} \mathrm{A}$. This proves (ii). Suppose $\mathrm{A}$ is $\mathrm{ij}-$ preclosed. Then $C l_{\mathrm{i}} I n t_{\mathrm{j}} \mathrm{A} \subseteq \mathrm{A}$ that implies $I n t_{\mathrm{j}} \mathrm{A}=\operatorname{Int} t_{\mathrm{j}} C l_{\mathrm{i}}$ $I n t_{\mathrm{j}} \mathrm{A}$ that proves that $\mathrm{A}$ is $\mathrm{j}$-near to $C l_{\mathrm{i}} I n t_{\mathrm{j}} \mathrm{A}$. This proves (iii) . Suppose A is ij- $\beta$-closed. Then $I n t_{\mathrm{i}} C l_{\mathrm{j}} I n t_{\mathrm{i}} \mathrm{A} \subseteq \mathrm{A}$ that implies $I n t_{\mathrm{i}} \mathrm{A}=I n t_{\mathrm{i}} C l_{\mathrm{j}} I n t_{\mathrm{i}} \mathrm{A}$ that proves that $\mathrm{A}$ is $\mathrm{i}$-near to $C l_{\mathrm{j}} I n t_{\mathrm{i}} \mathrm{A}$. Suppose $\mathrm{A}$ is ij-bclosed or $\mathrm{ij}-\mathrm{b}^{\#}$-closed then $\mathrm{A} \supseteq I n t_{\mathrm{i}} C l_{\mathrm{j}} \mathrm{A} \cap C l_{\mathrm{j}} I n t_{\mathrm{i}} \mathrm{A}$ that implies $I n t_{\mathrm{i}} \mathrm{A} \supseteq I n t_{\mathrm{i}} C l_{\mathrm{j}} \mathrm{A} \cap I n t_{\mathrm{i}} C l_{\mathrm{j}} I n t_{\mathrm{i}} \mathrm{A}=I n t_{\mathrm{i}} C l_{\mathrm{j}} I n t_{\mathrm{i}} \mathrm{A} \supseteq$ $I n t_{\mathrm{i}} \mathrm{A}$ that proves that $I n t_{\mathrm{i}} \mathrm{A}=I n t_{\mathrm{i}} C l_{\mathrm{j}} I n t_{\mathrm{i}} \mathrm{A}$. This proves that $\mathrm{A}$ is i-near to $C l_{\mathrm{j}} I n t_{\mathrm{i}} \mathrm{A}$. This proves (iv).

Lemma 3.8: Let A be ij-near to $B$ and $C$ be ij-near to D. Then

(i) $\quad \mathrm{A} \cap \mathrm{C}$ is ij-near to $\mathrm{B} \cap \mathrm{D}$.

(ii) $A \cup C$ is not ij-near to $B \cup D$.

Proof: Since A is ij-near to $B$ and since $C$ is ij-near to $\mathrm{D}, I n t_{\mathrm{i}} \mathrm{A}=I n t_{\mathrm{j}} \mathrm{B}$ and $I n t_{\mathrm{i}} \mathrm{C}=I n t_{\mathrm{j}} \mathrm{D}$. This implies $\operatorname{Int} t_{\mathrm{i}} \mathrm{A} \cap \operatorname{Int} t_{\mathrm{i}} \mathrm{C}=\operatorname{In} t_{\mathrm{j}} \mathrm{B} \cap \operatorname{Int} t_{\mathrm{j}} \mathrm{D}$ that implies $\operatorname{Int} t_{\mathrm{i}}(\mathrm{A} \cap \mathrm{C})=$ $I n t_{\mathrm{j}}(\mathrm{B} \cap \mathrm{D})$. This proves that $\mathrm{A} \cap \mathrm{C}$ is ij-near to $\mathrm{B} \cap \mathrm{D}$ that implies (i). Since $I n t_{\mathrm{i}}(\mathrm{A} \cup \mathrm{C}) \neq \operatorname{In} t_{\mathrm{i}} \mathrm{A} \cup \operatorname{Int} t_{\mathrm{i}} \mathrm{C}$, it follows that $A \cup C$ is not ij-near to $B \cup D$.

It is easy to see that the relation " is ij-near to " is not reflexive. Further this relation is neither symmetric nor transitive.

Lemma 3.9: Let $O_{i}$ be $i$-open and $O_{j}$ be $j$-open in $\left(\mathrm{X}, \tau_{1}, \tau_{2}\right)$.

(i) $\quad \mathrm{O}_{\mathrm{i}}$ is ij-near to $\mathrm{B}$ if and only if $\mathrm{O}_{\mathrm{i}}=\operatorname{Int} t_{\mathrm{j}} \mathrm{B}$.

(ii) $\quad \mathrm{A}$ is ij-near to $\mathrm{O}_{\mathrm{j}}$ if and only if $\operatorname{Int} \mathrm{t}_{\mathrm{i}} \mathrm{A}=\mathrm{O}_{\mathrm{j}}$.

\section{Proposition 3.10:}

(i). For each i-open set $\mathrm{O}_{\mathrm{i}}, \mathrm{B}=\left\{\mathrm{B} \subseteq \mathrm{X}: \mathrm{O}_{\mathrm{i}}\right.$ is ij-near to $\left.\mathrm{B}\right\}$ is a base for some topology on $\mathrm{Y}$ where $\mathrm{Y}$ is the union of all members of $\mathrm{B}$.

(ii). For each j-open set $O_{j}, A=\left\{A \subseteq X\right.$ : $A$ is ij-near to $\left.O_{j}\right\}$ is a base for some topology on $\mathrm{Z}$ where $\mathrm{Z}$ is the union of all members of $\mathrm{A}$.
Proof: Let $Y$ be the union of members of $B$. Suppose $A \in B$ and $B \in B$. Then $O_{i}$ is ij-near to $A \cap B$. This implies B is a base for some topology $\tau\left(\mathrm{O}_{\mathrm{i}}\right)$ on $\mathrm{Y}$. Similarly we can prove that $\mathrm{A}$ is a base for some topology $\tau\left(\mathrm{O}_{\mathrm{j}}\right)$ on $\mathrm{Z}$.

Remark 3.11: The topologies $\tau\left(\mathrm{O}_{\mathrm{i}}\right)$ and $\tau\left(\mathrm{O}_{\mathrm{j}}\right)$ can be extended to the topologies on $\mathrm{X}$. In fact $\tau\left(\mathrm{O}_{\mathrm{i}}\right) \cup\{\mathrm{X}\}$ and $\tau\left(\mathrm{O}_{\mathrm{j}}\right) \cup\{\mathrm{X}\}$ are topologies on $\mathrm{X}$ induced by the $\mathrm{i}$-open set $\mathrm{O}_{\mathrm{i}}$ and $\mathrm{j}$-open set $\mathrm{O}_{\mathrm{j}}$ respectively.

Remark 3.12: Every pair $\left(\mathrm{O}_{\mathrm{i},}, \mathrm{O}_{\mathrm{j}}\right)$ of open sets induces a bitopology on $\mathrm{X}$. In particular $\left(\mathrm{O}_{1}, \mathrm{O}_{2}\right)$ and $\left(\mathrm{O}_{2}, \mathrm{O}_{1}\right)$ induce bitopologies on $\mathrm{X}$.

Proposition 3.13: Let $A$ be ij-near to $B$ and $B \subseteq A$. Then

(i).If $A$ is $i j$-semiopen then $B$ is $j$-semiopen.

(ii).If $A$ is $i j-\alpha$-open then $B$ is $j$-semiopen.

(iii).If $B$ is ij-preclosed then $A$ is i-preclosed.

Proof: Suppose $\mathrm{A}$ is $\mathrm{ij}$-semiopen. Then $\mathrm{A} \subseteq C l_{\mathrm{j}} I n t_{\mathrm{i}} \mathrm{A}$. Since $\mathrm{A}$ is ij-near to $\mathrm{B}, \quad \operatorname{Int} \mathrm{A}=\operatorname{In} t_{\mathrm{j}} \mathrm{B}$ that implies $\mathrm{B} \subseteq \mathrm{A} \subseteq C l_{\mathrm{j}} I n t_{\mathrm{i}} \mathrm{A}=C l_{\mathrm{j}} I n t_{\mathrm{j}} \mathrm{B}$. This proves that $\mathrm{B}$ is $\mathrm{j}-$ semiopen that proves (i).

Suppose $\mathrm{A}$ is $\mathrm{ij}-\alpha$-open. Then $\mathrm{A} \subseteq I n t_{\mathrm{i}} C l_{\mathrm{j}} I n t_{\mathrm{i}} \mathrm{A}$. Since $\mathrm{A}$ is ij-near to $\mathrm{B}, \quad I n t_{\mathrm{i}} \mathrm{A}=\operatorname{Int} \mathrm{B}$ that implies $\mathrm{B} \subseteq \mathrm{A} \subseteq$ $I n t_{\mathrm{i}} C l_{\mathrm{j}} I n t_{\mathrm{i}} \mathrm{A}=I n t_{\mathrm{i}} C l_{\mathrm{j}} I n t_{\mathrm{j}} \mathrm{B} \subseteq C l_{\mathrm{j}} I n t_{\mathrm{j}} \mathrm{B}$. This proves that $\mathrm{B}$ is $\mathrm{j}$-semiopen that proves (ii). Suppose $\mathrm{B}$ is $\mathrm{ij}$ preclosed. Then $\mathrm{B} \supseteq C l_{\mathrm{i}} I n t_{\mathrm{j}} \mathrm{B}$. Since $\mathrm{A}$ is ij-near to $\mathrm{B}$, $I n t_{\mathrm{i}} \mathrm{A}=I n t_{\mathrm{j}} \mathrm{B}$ that implies $\mathrm{A} \supseteq \mathrm{B} \supseteq C l_{\mathrm{i}} I n t_{\mathrm{j}} \mathrm{B}=C l_{\mathrm{i}} I n t_{\mathrm{i}} \mathrm{A}$. This proves that $\mathrm{A}$ is $\mathrm{i}$-preclosed that proves (iii).

\section{CLOSER RELATIONS IN BITOPOLOGY}

Definition 4.1: We say that $A$ is ij-closer (resp. ijsemicloser, resp. ij- $\alpha$-closer, resp. ij-precloser, resp. ij-

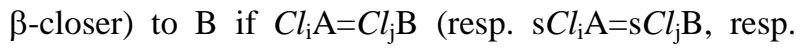
$\alpha C l_{\mathrm{i}} \mathrm{A}=\alpha C l_{\mathrm{j}} \mathrm{B}$, resp. $\mathrm{p} C l_{\mathrm{i}} \mathrm{A}=\mathrm{p} C l_{\mathrm{j}} \mathrm{B}$, resp. $\left.\beta C l_{\mathrm{i}} \mathrm{A}=\beta C l_{\mathrm{j}} \mathrm{B}\right)$.

\section{Proposition 4.2:}

(i). A is ij-closer to B if and only if B is ji-closer to A.

(ii).A is ij-semi-closer to B if and only if $B$ is ji-semicloser to $\mathrm{A}$.

(iii).A is ij- $\alpha$-closer to B if and only if $B$ is $j i-\alpha$-closer to $\mathrm{A}$. 


\section{International Journal of Research in Advent Technology, Vol.7, No.1, January 2019 E-ISSN: 2321-9637 Available online at www.ijrat.org}

(iv). $A$ is ij-pre-closer to $B$ if and only if $B$ is $j i-\alpha-$ closer to A.

(v). $A$ is ij- $\beta$-closer to B if and only if B is ji- $\alpha$-closer to A.

Proof: Straight forward.

Proposition 4.3: Let $A$ and $B$ be any two subsets of $X$ such that $\mathrm{X} \backslash C l_{\mathrm{i}} \mathrm{A} \in \tau_{\mathrm{j}}$ and $\mathrm{X} \backslash C l_{\mathrm{j}} \mathrm{B} \in \tau_{\mathrm{i}}$. If $\mathrm{A}$ is ij-semicloser or $\mathrm{ij}$ - $\alpha$-closer or $\mathrm{ij}$-pre-closer or $\mathrm{ij}$ - $\beta$-closer to $\mathrm{B}$ then $\mathrm{A}$ is $\mathrm{ij}$-closer to $\mathrm{B}$.

Proof: Suppose $\mathrm{A}$ is ij-semi closer to $\mathrm{B}$. Then $\mathrm{s} C l_{\mathrm{i}} \mathrm{A}=$ $\mathrm{s} C l_{\mathrm{j}} \mathrm{B}$ that implies

$\mathrm{A} \cup I n t_{\mathrm{i}} C l_{\mathrm{i}} \mathrm{A}=\mathrm{s} C l_{\mathrm{i}} \mathrm{A}={ }_{\mathrm{s}} C l_{\mathrm{j}} \mathrm{B}=\mathrm{B} \cup I n t_{\mathrm{j}} C l_{\mathrm{j}} \mathrm{B}$. Now $C l_{\mathrm{i}} \mathrm{A} \supseteq s C l_{\mathrm{i}} \mathrm{A}=\mathrm{s} C l_{\mathrm{j}} \mathrm{B}=\mathrm{B} \cup I n t_{\mathrm{j}} C l_{\mathrm{j}} \mathrm{B} \supseteq \mathrm{B}$ that implies $C l_{\mathrm{i}} \mathrm{A} \supseteq \mathrm{B}$. Since $\mathrm{X} \backslash C l_{\mathrm{i}} \mathrm{A} \in \tau_{\mathrm{j}}, C l_{\mathrm{i}} \mathrm{A} \supseteq C l_{\mathrm{j}} \mathrm{B}$. Similarly we can prove that $C l_{\mathrm{j}} \mathrm{B} \supseteq C l_{\mathrm{i}} \mathrm{A}$. This proves that $C l_{\mathrm{i}} \mathrm{A}=C l_{\mathrm{j}} \mathrm{B}$ that implies $\mathrm{A}$ is ij-closer to $\mathrm{B}$. The other cases can be analogously established.

\section{Proposition 4.4:}

(i).If $\mathrm{A}$ is ij-regular closed then $\mathrm{A}$ is closer to $I n t_{\mathrm{j}} \mathrm{A}$ in $\left(\mathrm{X}, \tau_{\mathrm{i}}\right)$

(ii). If $\mathrm{A}$ is $\mathrm{ij}$-semiopen or $\mathrm{ij}$ - $\alpha$-open then $\mathrm{A}$ is $\mathrm{j}$-closer to Int $_{\mathrm{i}} \mathrm{A}$.

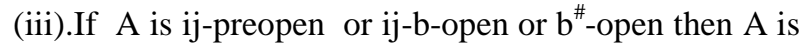
$\mathrm{j}$-closer to $\operatorname{Int}_{\mathrm{i}} \mathrm{Cl}_{\mathrm{j}} \mathrm{A}$.

(iv).If $\mathrm{A}$ is $\mathrm{ij}-\beta$-open then $\mathrm{A}$ is $\mathrm{i}$-closer to $I n t_{\mathrm{j}} \mathrm{A}$.

Proof: Suppose A is ij-regular closed. Then $\mathrm{A}=C l_{\mathrm{i}} \operatorname{Int}_{\mathrm{j}} \mathrm{A}$ that implies $C l_{\mathrm{i}} \mathrm{A}=C l_{\mathrm{i}} I n t_{\mathrm{j}} \mathrm{A}$. This proves that $\mathrm{A}$ is $\mathrm{i}-$ closer to $I n t_{\mathrm{j}} \mathrm{A}$. This proves (i). Suppose $\mathrm{A}$ is $\mathrm{ij}-$ semiopen. Then $C l_{\mathrm{j}} \mathrm{A}=C l_{\mathrm{j}} I n t_{\mathrm{i}} \mathrm{A}$ that implies $\mathrm{A}$ is $\mathrm{j}$-closer $I n t_{\mathrm{i}} \mathrm{A}$. Suppose $\mathrm{A}$ is $\mathrm{ij}$ - $\alpha$-open. Then $\mathrm{A} \subseteq I n t_{\mathrm{i}} C l_{\mathrm{j}} I n t_{\mathrm{i}} \mathrm{A}$ that implies $C l_{\mathrm{j}} \mathrm{A}=C l_{\mathrm{j}} I n t_{\mathrm{i}} C l_{\mathrm{j}} I n t_{\mathrm{i}} \mathrm{A}$ that proves that $\mathrm{A}$ is $\mathrm{j}$ closer to $I n t_{\mathrm{i}} \mathrm{A}$. This proves (ii). Suppose $\mathrm{A}$ is $\mathrm{ij}-$ preopen. Then $\mathrm{A} \subseteq \operatorname{Int}_{\mathrm{i}} C l_{\mathrm{j}} \mathrm{A}$ that implies $C l_{\mathrm{j}} \mathrm{A}=C l_{\mathrm{j}} I n t_{\mathrm{i}} C l_{\mathrm{j}} \mathrm{A}$ that proves that $\mathrm{A}$ is $\mathrm{j}$-closer to $\operatorname{Int}_{\mathrm{i}} C l_{\mathrm{j}} \mathrm{A}$. Suppose $\mathrm{A}$ is $\mathrm{ij}-\mathrm{b}$-open or $\mathrm{ij}-\mathrm{b}^{\#}$-open. Then $\mathrm{A} \subseteq \operatorname{Int}_{\mathrm{i}} C l_{\mathrm{j}} \mathrm{A} \cup C l_{\mathrm{j}} I n t_{\mathrm{i}} \mathrm{A} \quad$ that implies $C l_{\mathrm{j}} \mathrm{A} \subseteq C l_{\mathrm{j}} I n t_{\mathrm{i}} C l_{\mathrm{j}} \mathrm{A} \cup C l_{\mathrm{j}} I n t_{\mathrm{i}} \mathrm{A}=\quad C l_{\mathrm{j}} I n t_{\mathrm{i}} C l_{\mathrm{j}} \mathrm{A} \subseteq C l_{\mathrm{j}} \mathrm{A} \quad$ that proves that $C l_{\mathrm{j}} \mathrm{A}=C l_{\mathrm{j}} I n t_{\mathrm{i}} C l_{\mathrm{j}} \mathrm{A}$. This proves that $\mathrm{A}$ is $\mathrm{j}$ closer to $I n t_{\mathrm{i}} C l_{\mathrm{j}} \mathrm{A}$. This proves (iii). Suppose $\mathrm{A}$ is $\mathrm{ij}-\beta$ open. Then $\mathrm{A} \subseteq C l_{\mathrm{i}} I n t_{\mathrm{j}} C l_{\mathrm{i}} \mathrm{A}$ that implies
$C l_{\mathrm{i}} \mathrm{A}=C l_{\mathrm{i}} I n t_{\mathrm{j}} C l_{\mathrm{i}} I n t_{\mathrm{j}} \mathrm{A}=C l_{\mathrm{i}} \operatorname{Int}_{\mathrm{j}} \mathrm{A}$ that proves that $\mathrm{A}$ is $\mathrm{i}-$ closer to $I n t_{\mathrm{j}} \mathrm{A}$. This proves (iv).

Lemma 4.5: $A$ is $i j$-near to $B$ iff $X \backslash A$ is $i j$-closer to $\mathrm{X} \backslash \mathrm{B}$.

Proof: Since $\mathrm{A}$ is $\mathrm{ij}$-near to $\mathrm{B}, \operatorname{Int}_{\mathrm{i}} \mathrm{A}=\operatorname{Int} t_{\mathrm{j}} \mathrm{B}$ that implies $C l_{\mathrm{i}}(\mathrm{X} \backslash \mathrm{A})=C l_{\mathrm{j}}(\mathrm{X} \backslash \mathrm{B})$. This proves that $\mathrm{X} \backslash \mathrm{A}$ is $\mathrm{ij}$ closer to $\mathrm{X} \backslash \mathrm{B}$. The converse part is analogous.

Lemma 4.6: Let $A$ be ij-closer to $B$ and $C$ be ij-closer to D. Then

(i). $A \cup C$ is ij-closer to $B \cup D$.

(ii). $\mathrm{A} \cap \mathrm{C}$ is not $\mathrm{ij}$-closer to $\mathrm{B} \cap \mathrm{D}$.

Proof: Since A is ij-closer to B and $\mathrm{C}$ is ij-closer to $\mathrm{D}$, $C l_{\mathrm{i}} \mathrm{A}=C l_{\mathrm{j}} \mathrm{B}$ and $C l_{\mathrm{i}} \mathrm{C}=C l_{\mathrm{j}}$ D. This implies $C l_{\mathrm{i}} \mathrm{A} \cup C l_{\mathrm{i}} \mathrm{C}=C l_{\mathrm{j}}$ $\mathrm{B} \cup C l_{\mathrm{j}} \mathrm{D}$ that implies $C l_{\mathrm{i}}(\mathrm{A} \cup \mathrm{C})=C l_{\mathrm{j}}(\mathrm{B} \cup \mathrm{D})$. This proves that $\mathrm{A} \cup \mathrm{C}$ is $\mathrm{ij}$-closer to $\mathrm{B} \cup \mathrm{D}$ that implies (i). Since $C l_{\mathrm{i}}$ $(\mathrm{A} \cap \mathrm{C}) \neq C l_{\mathrm{i}} \mathrm{A} \cap C l_{\mathrm{i}} \mathrm{C}$, it follows that $\mathrm{A} \cap \mathrm{C}$ is not $\mathrm{ij}-$ closer to $\mathrm{B} \cap \mathrm{D}$.

This proves (ii).

Lemma 4.7: Let $F_{i}$ be i-closed and $F_{j}$ be $j$-closed in $\left(\mathrm{X}, \tau_{1}, \tau_{2}\right)$. Then

(i) $\quad \mathrm{F}_{\mathrm{i}}$ is ij-closer to $\mathrm{B}$ if and only if $\mathrm{F}_{\mathrm{i}}=C l_{\mathrm{j}} \mathrm{B}$.

(ii) $\quad \mathrm{A}$ is ij-closer to $\mathrm{F}_{\mathrm{j}}$ if and only if $C l_{\mathrm{i}} \mathrm{A}=\mathrm{F}_{\mathrm{j}}$

Proposition 4.8: Let $\mathrm{A}$ be $\mathrm{ij}$-closer to $\mathrm{B}$ and $\mathrm{B} \subseteq \mathrm{A}$. Then

(i).If $A$ is ji-preopen then $B$ is $j$-preopen.

(ii).If $\mathrm{B}$ is ji-semiclosed then $\mathrm{A}$ is $\mathrm{i}$-semiclosed.

(iii).If $\mathrm{B}$ is $\mathrm{ji}-\alpha$-closed then $\mathrm{A}$ is $\mathrm{i}$-semiclosed.

Proof: Suppose $\mathrm{A}$ is ji-preopen. Then $\mathrm{A} \subseteq \operatorname{Int}_{\mathrm{j}} C l_{\mathrm{i}} \mathrm{A}$. Since $\mathrm{A}$ is ij-closer to $\mathrm{B}, C l_{\mathrm{i}} \mathrm{A}=C l_{\mathrm{j}} \mathrm{B}$ that implies $\mathrm{B} \subseteq \mathrm{A} \subseteq$ $I n t_{\mathrm{j}} C l_{\mathrm{i}} \mathrm{A}=I n t_{\mathrm{j}} C l_{\mathrm{j}} \mathrm{B}$. This proves that $\mathrm{B}$ is $\mathrm{j}$-preopen that proves (i).

Suppose B is ji-semiclosed. Then $\mathrm{B} \supseteq \operatorname{Int}_{\mathrm{i}} C l_{\mathrm{j}} \mathrm{B}$. Since $\mathrm{A}$ is ij-closer to $\mathrm{B}, \quad C l_{\mathrm{i}} \mathrm{A}=C l_{\mathrm{j}} \mathrm{B}$ that implies $\mathrm{A} \supseteq \mathrm{B} \supseteq I n t_{\mathrm{i}} C l_{\mathrm{j}} \mathrm{B}=I n t_{\mathrm{i}} C l_{\mathrm{i}} \mathrm{A}$. This proves that $\mathrm{A}$ is $\mathrm{i}$ semiclosed that proves (ii).

Suppose B is ji- $\alpha$-closed. Then $\mathrm{B} \supseteq C l_{\mathrm{j}} I n t_{\mathrm{i}} C l_{\mathrm{j}} \mathrm{B}$. Since A is ij-closer to $\mathrm{B} \quad C l_{\mathrm{i}} \mathrm{A}=C l_{\mathrm{j}} \mathrm{B}$ that implies $\mathrm{A} \supseteq \mathrm{B} \supseteq$ $C l_{\mathrm{j}} I n t_{\mathrm{i}} C l_{\mathrm{j}} \mathrm{B} \supseteq I n t_{\mathrm{i}} C l_{\mathrm{j}} \mathrm{B}=I n t_{\mathrm{i}} C l_{\mathrm{i}} \mathrm{A}$. This proves that $\mathrm{A}$ is $\mathrm{i}$-semiclosed that proves (iii). 


\section{International Journal of Research in Advent Technology, Vol.7, No.1, January 2019 E-ISSN: 2321-9637 \\ Available online at www.ijrat.org}

\section{CONCLUSION}

Nearly open sets and nearly closed sets in bi topological spaces are characterized by using the near and closer relations introduced between the two topologies on a bitoplogical space. It has been established that every near class is a base for some topology.

\section{REFERENCES}

[1].M.E.Abd El-Monsef S.N. El-Deeb, and R.A.Mohmoud, " $\beta$-open sets and $\beta$-continuous mappings", Bull. Fac. Sci. Assiut Univ., vol.12, pp.77-90, 1983.

[2]. D.Andrijevic, "On b-open sets", Mat.Vestnik, vol.18, pp.59-64, 1996.

[3]. R. Chitralekha, M. Anitha and N. Meena, " $b^{\#}$ open sets in bi-topological spaces", International Conference on Computing Sciences, ICCS-2018, January 8 \& 9, 2018, Loyola Colleg , Chennai, India ( Mathematical Sciences International Research Journal), vol.7, no.2,pp.103-105, 2018(spl.issue).

[4]. R. Chitralekha, M. Anitha and N. Meena, "Near and closer relations in topology", Rajagiri School of Engg.\&Tech., Kochi, Kerala, India, Dec. 5-11, 2018.

[5]. Dvalishvili, "Bitopological spaces:Theory Relations with Generalized Algebraic Structuresand Applications", North-Holland Mathematics studies Elsevier Science B.V Anasterdam Vol.199, 2005.

[6]. N.Levine, "Semi-open sets and semi continuity in topological spaces", Amer. Math. Monthly, vol.70, pp.36-41, 1963.

[7]. A.S.Mashhour, M.E.Abd El-Monsef and S.N.ElDeeb , "On pre-continuous and weak precontinuous functions", Proc. Math. Phys. Soc. Egypt, vol.53, pp.47-53, 1982.

[8]. O.Njastad , "Some classes of nearly open sets", Pacific J.Math., vol.15, 961-970, 1965.

[9]. M.H.Stone, "Application of the theory of Boolean rings to the general topology", Tran. A.M.S. vol.41, pp.375-481, 1937.

[10]. G.Thamizharasi and P.Thangavelu, "Studies in Bitopological Spaces", Ph.D, Thesis, Manonmaniam Sundaranar University, Tirunelveli12, India, 2010.

[11]. R.Usha Parameswari and P.Thangavelu, "On $\mathrm{b}^{\#}$-open sets", International Journal of Mathematics Trends and Technology, vol.3, no.5, pp.202 - 218, 2014.

[12]. J.D. Weston, "On the comparison of topologies", J.London Math. Soc. vol.32, pp. 342-354, 1957. 